\title{
Quality of life in arthritis patients and its correlation with anxiety and depression
}

\author{
Siddiqui $\mathbf{F}^{1}$, Tripathi $\mathbf{N}^{2}$ \\ ${ }^{1}$ Dr. Faisal Siddiqui, Senior Resident, Department of Psychiatry, All India Institute of Medical Sciences, \\ Bhopal, ${ }^{2}$ Dr. Neeraj Tripathi, Assistant Professor, Department of Medicine, Hind Institute of Medical Science, \\ Safidabad, Barabanki, U.P, India.
}

Address for Correspondence: Dr Neeraj Tripathi, Assistant Professor, Department of Medicine, Hind Institute of Medical Science, Safidabad, Barabanki, U.P. E-mail address: drneeraj3@gmail.com

\begin{abstract}
Background: Although the medical and economic consequences of arthritis are of great concern to researchers and clinicians, this disease also affects an individual's capacity to live a full and active life. Aim: To study the correlation between depression, anxiety and quality of life among Indian adults suffering from arthritis in a tertiary care centre. Material and Methods: The study sample comprised of adults age above 30 years with clinician diagnosed arthritis $(\mathrm{n}=370)$. Depression and anxiety were measured using separate and validated scales. Prevalence was estimated for the sample overall and stratified by subgroups. Associations between correlates and each condition were estimated with prevalence ratios. Result: Depression is significantly negatively correlated to quality of life $(\mathrm{r}-0.34 \mathrm{P}=0.0001)$. Anxiety also negatively correlated to quality of life $(\mathrm{r}-0.24 \mathrm{P}=0.0001)$. Anxiety and depressed patients differed significantly from other arthritic patients in terms of quality of life. (F value 41 and $\mathrm{P}$ value 0.0001 ) subjects having both depression and anxiety had the poorest quality of life. Conclusion: Screening for anxiety and depression should form an essential part of the clinical workup of patients suffering from arthritis. Identification of anxiety and depression in subjects suffering from arthritis will have definite implications for comprehensive management of patients.
\end{abstract}

Keywords: Arthritis, Anxiety, Depression, Quality of life.

\section{Introduction}

Rheumatoid arthritis is a chronic systemic disease that affects joints, muscles, tendons and connective tissue. Its prevalence ranges from 0.3 to $1 \%$ in adults, affects 21 million and accounts for about 5 million DALY worldwide. Osteoarthritis is a degenerative joint disease which mainly affects the articular cartilage. $10 \%$ of people above 60 have symptoms of osteoarthritis. It is the 10th leading cause of nonfatal burden in the world and accounts for 15 million DALYs globally [1].

These diseases which include such varied conditions as rheumatoid arthritis, osteoarthritis, gout, ankylosing spondylitis, psoriatic arthritis, systemic lupus erythymatosis and spondyloarthropathies often cause severe pain and emotional

Manuscript received: $10^{\text {th }}$ July 2017

Reviewed: $20^{\text {th }}$ July 2017

Author Corrected: $29^{\text {th }}$ July 2017

Accepted for Publication: $4^{\text {th }}$ August 2017 suffering that may contribute to disability, interfere with physical mobility and declines in health related quality of life in many patients [2].

Despite their slow development arthritis are progressive in nature and eventually lead to joint destruction, significant loss of function and reduced quality of life in many patients. Psychosocial factors are being suggested as mediators or moderators in the mediation of relation between arthritis and psychological functioning [3].

The prevalence of anxiety and depression in arthritis is higher than that of general population. In recent times; large scale interest has been generated in the study of psychiatric and medical comorbidity in health service research and psychiatric epidemiology [4]. 
Although the medical and economic consequences of arthritis are of great concern to researchers and clinicians, this disease also affects an individual's capacity to live a full and active life. Thus, it has increasingly become clear that the problems associated with arthritis are not simply medical ones; it also appears to have a substantial impact on a person's functional capacity and quality of life [5].

\section{Materials and Methods}

It was a cross-sectional observational study conducted in a tertiary care health center in central India. 370 consecutive patients who had arthritis were selected as per inclusion and exclusion criteria.

Institutional research and ethical committee approval was obtained prior to the study. Informed consent was obtained from each patient to participate in the study was obtained. Inclusion criteria is subjects between ages of 18 and 70 years and subjects diagnosed as suffering from various types of arthritis by orthopaedicians, rheumatologists and physicians and Exclusion criteria is patients with presence of psychosis, substance use disorders, and mental retardation.

Procedure: Sociodemographic and clinical data were obtained and meticulously documented on a specially prepared proforma. The following psychological instruments were used to obtain information about depression, anxiety and quality of life in every case. The Investigator was not involved in the management of the cases.

1. Zung self rating depression scale: This is a 20 item self rating anxiety scale measuring cognitive, autonomic, m0tor and central nervous symptoms on a Likert scale ranging from 1 to 4 . It yields a maximum score of 80 and minimum 20. A cut off score of 45 used to identify anxiety [6].

2. Zung self rating anxiety scale: This is a self rating scale of depression having 20 items. Each item is measured on a scale 1 to 4 . The scale yields a maximum score of 80 . A cut off score of 45 is used to identify depression [7].

3. The WHOQOL-BREF contains a total of 26 questions to provide broad and comprehensive assessment one item from each of the 24 facets contained in WHOQOL-100 has been included. In addition 2 items from overall quality of life and general health has been included. Each item is measured on a Likert scale ranging from 1-5.

Raw scores obtained from each of the four dimensions are transformed into WHOQOL-100 standard scores by means of a key provided. Scores from each dimension is added up to obtain a summary score [8].

Statistical Analysis: Obtained data were subjected to statistical analysis using SPSS software version 20.0. Correlation was found by Pearson product moment correlation.

\section{Results}

In our study, out of total 370 cases of arthritis almost two thirds were females (64\%) and (36\%) were males. $78 \%$ were urban dwelling. $90 \%$ were married but a substantial number were widowed $(8 \%)$, $65 \%$ were unemployed, $59 \%$ belonged to nuclear families. $55 \%$ belonged to low economic status. Three quarters of the patients $(75 \%)$ had primary/secondary education. $60 \%$ of Rheumatoid Arthritis (RA) cases were below 50 years of age while $66.5 \%$ of Osteoarthritis cases were above 50 years of age. Distribution of the subjects according to the presence of anxiety and depression is shown in Table No. 1.

In the study subjects $24.3 \%$ had depression $11.3 \%$ had anxiety $8.1 \%$ had both anxiety and depression. Females suffered significantly more anxiety and depression than males. Nuclear families were represented (86.7\% vs. 52$58 \%)$

$53 \%$ of arthritis subjects who suffered anxiety were below 50 years of age while only $26 \%$ of depressed patients were below 50 years of age. $74 \%$ of the depressed groups were above 50 years of age while only $47 \%$ of the anxious groups were above 50 years of age. 53\% of mixed anxiety and depression group also were below 50 years of age. Distribution of the subjects according to the anxiety, depression and quality of life scores is shown in table no. 2. 
Table No.-1: Distribution of the subjects according to the presence of anxiety and depression.

\begin{tabular}{|c|c|c|c|c|}
\hline Gender & Anxiety & Depression & Mixed anxiety and depression & Normal \\
\hline Male & 12 & 26 & 4 & 90 \\
\hline Female & 30 & 64 & 26 & 118 \\
\hline \multicolumn{5}{|c|}{ Marital Status } \\
\hline Married & 38 & 82 & 20 & 194 \\
\hline Bachelor & 2 & 0 & 1 & 1 \\
\hline Widowed & 2 & 6 & 8 & 12 \\
\hline Divorced & 0 & 2 & 1 & 1 \\
\hline \multicolumn{5}{|c|}{ Family Pattern } \\
\hline Nuclear & 22 & 50 & 26 & 120 \\
\hline Extended & 20 & 40 & 4 & 88 \\
\hline \multicolumn{5}{|c|}{ Occupation } \\
\hline Employed & 18 & 28 & 6 & 78 \\
\hline Unemployed & 24 & 62 & 24 & 130 \\
\hline \multicolumn{5}{|c|}{ Age Group } \\
\hline Less than 40 & 2 & 6 & 2 & 35 \\
\hline $41-50 y r s$ & 20 & 17 & 14 & 50 \\
\hline $51-60 y r s$ & 14 & 36 & 4 & 73 \\
\hline More than $60 \mathrm{yrs}$ & 6 & 31 & 10 & 50 \\
\hline
\end{tabular}

Depression is significantly negatively correlated to quality of life $(\mathbf{r}-\mathbf{0 . 3 4} \mathbf{P}=\mathbf{0 . 0 0 0 1})$. Anxiety also negatively correlated to quality of life $(\mathbf{r}-\mathbf{0 . 2 4} \mathbf{P}=\mathbf{0 . 0 0 0 1})$. Anxiety and depressed patients differed significantly from other arthritic patients in terms of quality of life. (F value 41and $\mathbf{P}$ value $\mathbf{0 . 0 0 0 1}$ ) subjects having both depression and anxiety had the poorest quality of life.

Table No.-2: Distribution of the subjects according to the anxiety, depression and quality of life scores.

\begin{tabular}{|c|c|c|c|c|c|}
\hline $\begin{array}{c}\text { Quality of } \\
\text { life scores }\end{array}$ & $\begin{array}{c}\text { No. of Subjects } \\
\mathbf{n = 3 7 0}(\%)\end{array}$ & $\begin{array}{c}\text { Anxiety } \\
\text { Scores }\end{array}$ & $\begin{array}{c}\text { No. of Subjects } \\
(\mathbf{n = 3 7 0})\end{array}$ & $\begin{array}{c}\text { Depression } \\
\text { Scores }\end{array}$ & $\begin{array}{c}\text { No. of Subjects } \\
(\mathbf{n = 3 7 0})\end{array}$ \\
\hline $88-123$ & $12(3.24 \%)$ & $21-29$ & $146(39.46 \%)$ & $21-29$ & $110(29.73 \%)$ \\
\hline $124-159$ & $36(9.73 \%)$ & $30-38$ & $108(29.19 \%)$ & $30-38$ & $90(24.32 \%)$ \\
\hline $160-195$ & $92(24.86 \%)$ & $39-47$ & $58(15.68 \%)$ & $39-47$ & $74(20.00 \%)$ \\
\hline $196-231$ & $94(25.41 \%)$ & $48-56$ & $44(11.89 \%)$ & $48-56$ & $78(21.08 \%)$ \\
\hline $232-267$ & $76(20.54 \%)$ & $57-65$ & $10(2.70 \%)$ & $57-65$ & $16(4.32 \%)$ \\
\hline $268-303$ & $52(14.05 \%)$ & $66-74$ & $04(1.08 \%)$ & $66-74$ & $2(0.54 \%)$ \\
\hline $304-339$ & $8(2.16 \%)$ & $>74$ & $00(00 \%)$ & $>74$ & $00(00 \%)$ \\
\hline
\end{tabular}

\section{Discussion}

In the present study $42.8 \%$ of the subjects were found to have anxiety and/or depression. $23.4 \%$ of the subjects had depression, $11.3 \%$ had anxiety and $8.1 \%$ had both anxiety and depression. Quite a substantial number of studies reported preponderance of anxiety [9, 10]. However the findings are in agreement with other studies [11, $12,13]$.
In the present study $8.1 \%$ had mixed anxiety and depression which is similar to Murphy et al who reported $8.4 \%$ but quite different from that reported by Isik et al $(15.9 \%)$. It is not possible to ascribe any cause for the discrepant results as different workers used different instruments and there could be many psychosocial, comorbid and other biological factors that underlay the phenomenon. 
In the present study females are seen to suffering more depression and anxiety which is conformity with the general trend. Stress may be playing a part in the occurrence of mixed anxiety and depression as $87 \%$ of them are from nuclear families in marked contrast to $52-58 \%$ in depression and anxiety respectively.

Further $33 \%$ of the mixed category is widowers whereas only 5 to $7 \%$ of Anxiety and depressive categories are widowers. Loneliness of a widower from nuclear family could be one important factor contributing to the occurrence of anxiety and depression together besides other disease related factors.

The present study shows that relatively younger arthritic patients are prone to anxiety whereas older people are more prone to depression. This is in conformity with the findings of Murphy et al [14].

Arthritic patients suffering from anxiety and depression found to have significantly poor health related quality of life (WHOQOL - BREF). This is in conformity with Reginster et al [15] and Dominik et al [16]. Subjects having both anxiety and depression appear to be having the worse (WHOQOL - BREF). The combined effect of anxiety and depression and associated with some psychosocial factors (widowhood, nuclear family) and pain seem to be contributing to the poor (WHOQOL - BREF) in those subjects having both anxiety and depression.

\section{Conclusion}

Screening for anxiety and depression should form an essential part of the clinical workup of patients suffering from arthritis. Identification of anxiety and depression in subjects suffering from arthritis will have definite implications for comprehensive management of patients.

Effective management of anxiety and depression by drugs and psychotherapy is likely to improve the clinical picture, suffering and quality of life.

\section{Funding: Nil, Conflict of interest: None Permission of IRB: Yes}

\section{References}

1. www. who. int/ healthinfo/ statistics/ bod osteoarthrits (Last accessed 21 Nov 2015).
2. Lokeshia A Sumner and Perry M Nicassio in: Perry M Nicassio. Ed Psychosocial Factors in Arthritis. Springer 2015)

3. M L Harris. Physical and clinical predictors. In: Perry M Nicassio. Ed Psychosocial Factors in Arthritis. Springer 2015.

4. DeVellis BM, DeVellis RF. Depression and arthritis. N C Med J. 2007 Nov-Dec;68(6):434-5.

5. Scott DL, Garrood T. Quality of life measures: use and abuse. Baillieres Best Pract Res Clin Rheumatol. 2000 Dec;14(4):663-87.

6. Zung WW. A rating instrument for anxiety disorders. Psychosomatics.1971 Nov-Dec; 12(6): 371-9.

7. Zung WW. A self rating depression scale. Arch Gen Psychiatry. 1965; 12:63-70.

8. Hennessy CH, Moriarty DG, Zack MM, Scherr PA, Brackbill R. Public Health Rep. 1994 Sep-Oct; 109 (5):665-72.

9. S Odegard, A Finset, $\mathrm{P}$ Mowinckel et al. Pain and psychological health status over 10 year period in patients with recent onset Rheumatoid arthritis. Annals of Rheumatic Diseases. 2007; 66: 1195 1201

10. Rogers HL, Brotherton HT, de Luis A, OliveraPlaza SL, Córdoba-Patiño AF, Peña-Altamar ML. Depressive symptoms are independently associated with pain perception in Colombians with rheumatoid arthritis. Acta Reumatol Port. 2015 JanMar;40(1):40-9.

11. $\mathrm{T}$ Takade, $\mathrm{N}$ Morimato, $\mathrm{N}$ Kinukewa et al. Factors affecting depression and anxiety in female Japanese patients with rheumatoid arthritis. Clinical and Experimental Rheumatology. 2000; 5: 101-12.

12. el-Miedany YM, el-Rasheed AH. Is anxiety a more common disorder than depression in rheumatoid arthritis? Joint Bone Spine. 2002 May;69(3):300-6.

13. Zyrianova Y, Kelly BD, Gallagher C, McCarthy C, Molloy MG, Sheehan J, Dinan TG. Depression and anxiety in rheumatoid arthritis: the 


\section{Original Research Article}

role of perceived social support. Ir J Med Sci. 2006 Apr-Jun;175(2):32-6.

14. Murphy LB, Sacks JJ, Brady TJ, Hootman JM, Chapman DP. Anxiety and depression among US adults with arthritis: prevalence and correlates. Arthritis Care Res (Hoboken). 2012 Jul;64(7):96876. doi: 10.1002/acr.21685.
15. Reginster JY. The prevalence and burden of arthritis. Rheumatology (Oxford).2002Apr;41 Supp $1: 3-6$.

16. Dominick KL, Ahern FM, Gold CH, Heller DA. Health-related quality of life among older adults with arthritis. Health Qual Life Outcomes. 2004 Jan 13;2:5.

\section{How to cite this article?}

Siddiqui F, Tripathi N. Quality of life in arthritis patients and its correlation with anxiety and depression. Int J Med Res Rev 2017;5(08):786-790.doi:10.17511/ijmrr. 2017.i08.02. 